\title{
Influence of Shot Peening on DIN 1.2714 Hot Work Tool Steel
}

\author{
Valmik Bhavar ${ }^{1}$, Sachin V. Patil1 ${ }^{1}$, Prakash Kattire' ${ }^{1}$, P. P. Date ${ }^{2}$, R. K. P. Singh ${ }^{1}$ \\ ${ }^{1}$ Kalyani Center for Technology and Innovation (KCTI), Bharat Forge Ltd., Pune, India \\ ${ }^{2}$ Indian Institute of Technology Bombay (IITB), Mumbai, India \\ Email: Valmik.bhawar@bharatforge.com
}

How to cite this paper: Bhavar, V., Patil, S.V., Kattire, P., Date, P.P. and Singh, R.K.P. (2017) Influence of Shot Peening on DIN 1.2714 Hot Work Tool Steel. Journal of Materials Science and Chemical Engineering, 5, 81-90.

http://dx.doi.org/10.4236/msce.2017.51012

Received: December 15, 2016

Accepted: January 13, 2017

Published: January 16, 2017

\begin{abstract}
Shot peening is one of the most popular surface enhancement technique used to improve fatigue performance of different materials. This paper focuses on to study the effect of different shot peening parameters on micro-structural and mechanical properties of DIN 1.2714 tool steel specimens. Shot peening treatments were carried out by varying shot size and peening intensity. X-ray stress analysis, micro-hardness testing and micro-structural analysis were performed to characterize these specimens. In addition, pin on disk wear testing was executed to recognize wear behavior of this shot peened tool steels. It was observed that along with compressive residual stress generation, shot peening also induces work hardening effect and modifies surface structure which are responsible for significant improvement in this tool steel.
\end{abstract}

\section{Keywords}

Shot Peening, Surface Enhancement Techniques, Tool Steel

\section{Introduction}

Shot peening is a process used to impart compressive residual stresses on the surface to improve mechanical properties of the materials [1]. In this process, component surface is exposed to high velocity bombardments of small spherical media (called as shot of metallic, glass or ceramic material). Each shot of media acts like a peening hammer which plastically deforms the material and creates small indentation called as dimple. The starched surface because of individual shot causes compressive stressed zone below the dimple shown in Figure 1. Part is bombarded with multiple shots producing number of overlapped dimples which results in uniform layer of compressive stress at the surface.

Shot peening is the most widely used surface treatment technique since it improves fatigue, hardness, wear, stress-corrosion cracking and so on [2]. Increase 

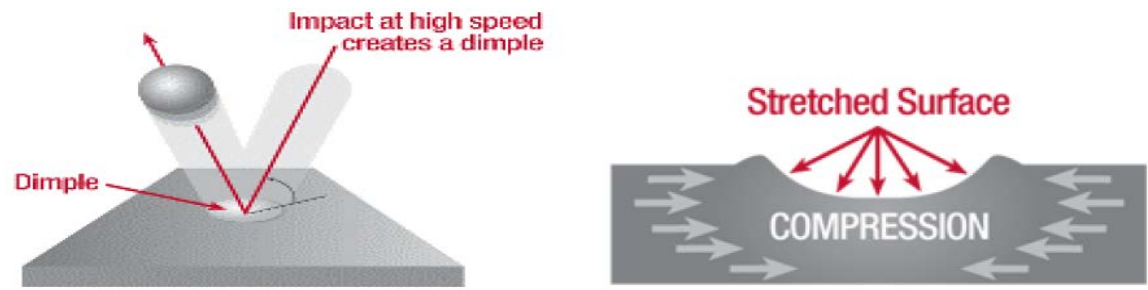

Figure 1. Mechanism of shot peening process [1].

in dislocation densities, cold work and generation of compressive residual stresses are the main mechanisms responsible for these improvements [3] [4]. The effectiveness of shot peening is decided by the magnitude of compressive residual stress and its effective depth from the surface.

Much research has been done on shot peening of various metals and its effect on fatigue life. In case of $\mathrm{Al}$ alloys, significant improvements in low cycle fatigue [5] and high cycle fatigue [3] were reported by employing shot peening at optimized parameters.

K. A. Soady et al. [6] investigated the effect of shot peening on notched low cycle fatigue of heat resistant alloy and revealed substantial improvements. A. T. Vielma et al. [7] examined impact of shot peening on quenched and tempered structural steel and informed that shot peening parameters must be optimized to have beneficial effect on fatigue life.

In case of tool steel materials, very few studies have been carried out to investigate improvement in fatigue and wear properties. G. H. Farrahi et al. [8] studied effect of various surface treatments on AISI D3 cold work tool steel and conveyed $14 \%$ improvement in fatigue life by using shot peening. Y. Harada et al. [9] did research on micro shot peening of high speed tool steel and claimed significant increase in fatigue performance. They also examined effect of processing temperature used during peening and reported enhanced peening effect at higher temperatures. Shih-Hsien Chang et al. [4] claimed 100\% - 200\% improvement in hot and cold forging die life. Most of the above mentioned research was focused on effect of shot peening on fatigue life. However, less prominence was given to its effect on wear behavior which is highly important as far as tool steels are concerned. This is the main focus of the presented investigations on the DIN 1.2714 hot work tool steel.

\section{Experimentation}

The commercial grades of DIN 1.2714 tool steel in harden and tempered condition was selected for this work. Table 1 shows chemical composition of this material which was analyzed by vacuum emission spectrometer. The hardness of this material in as received $(\mathrm{H} \& \mathrm{~T})$ condition was $30-32 \mathrm{HRC}$.

Small specimens of appropriate dimensions required for microstructural, mechanical and wear analysis were prepared from this material for planned research. All these prepared specimens were named as AR (as received) specimens.

Few specimens from AR group were then shot peened in bucket-type enclosed 
Table 1. Chemical composition of DIN 1.2714 tool steel (Harden and tempered condition).

\begin{tabular}{ccccccccccc}
\hline Elements & $\mathrm{C}$ & $\mathrm{Mn}$ & $\mathrm{Si}$ & $\mathrm{Cr}$ & $\mathrm{Ni}$ & $\mathrm{Mo}$ & $\mathrm{V}$ & $\mathrm{S}$ & $\mathrm{P}$ & $\mathrm{Fe}$ \\
\hline Weight \% & 0.520 & 0.80 & 0.250 & 1.11 & 1.70 & 0.450 & 0.100 & 0.003 & 0.025 & Remaining \\
\hline
\end{tabular}

and pressurized pneumatic machine by varying shot size and peening intensity. Two different sizes of cast steel shots $(0.4 \mathrm{~mm}$ and $0.8 \mathrm{~mm})$ with hardness ranging from 48 - 50 HRC were used in this experiment. For each shot size, compressed air pressure was varied in order to obtain different Almen intensities. All the shot peening treatments were produced by using working distance of 125 $\mathrm{mm}$ and peening coverage over $100 \%$. Intensity of shot peening was measured by an Almen gauge, and checked by using the standard A-strip. All the specimens treated in this manner were designated as SP1, SP2, SP3 and SP4 depending on shot peening parameters. All specimen treatment conditions used in this study are summarized in Table 2 .

\section{Characterization}

Microstructure, micro hardness, surface roughness, X-ray stress analysis and wear tests of the DIN1.2714 steel were conducted at room temperature in order to compare the effects of un-treated and shot peened specimens. SEM analysis was carried out to observe the change in surface characteristics due to shot peening. Micro hardness indentations with a load of $200 \mathrm{~g}$ were performed from the treated surface until a depth at which the initial hardness was not modified by the shot peening treatment. These tests were performed using a on Matsuawa with Celmex make micro-hardness tester according to the ASTM E384 standard. For effective case depth measurement, shot peened specimens were cut in transverse direction and mounted with bakelite powder at $175^{\circ} \mathrm{C}$. Cut faces of samples were then polished with 300 and $400 \mathrm{G}$ polish papers followed by cloth grinding with aluminum oxide paste. The hardness was measured at 15 locations which were kept $0.04 \mathrm{~mm}$ apart. Limiting case depth was determined by adding $50 \mathrm{HV}$ to core material hardness of same sample.

Residual stress profiles generated by shot peening were determined by X-ray diffraction (XRD) and incremental layer removal by electro polishing. The X-ray diffraction technique used in the present study to determine residual macro-stresses was the $\sin ^{2} \psi$ method [7]. Measurements were made by using an "Xstress 3000" device as per ASTM000 standard. A Cr-Ka X-ray source was used employing a wavelength of $0.229 \mathrm{~nm}$ and measurements were taken on the (211) diffraction peak of the martensite, which was recorded at a $2 \theta$ angle of approximately $156^{\circ}$. "Xstress $3000^{\prime}$ measuring device along with electro polishing equipment is shown in Figure 2.

The surface roughness, $R a$ value, was determined for all samples at three locations by using a Taylor Hobson Form Talysurf 120L stylus profilometer in accordance with BS EN ISO 4287:2000. Average of these three different readings was taken as measure of surface roughness. 
Table 2. Sample treatments and their nomenclature.

\begin{tabular}{cccc}
\hline Shot Size $(\mathrm{mm})$ & Intensity & Pressure $\left(\mathrm{Kg} / \mathrm{cm}^{2}\right)$ & Nomenclature \\
\hline 0.4 & $0.3 \mathrm{~A}$ & 1.5 & $\mathrm{SP} 1$ \\
0.4 & $0.5 \mathrm{~A}$ & 3.5 & $\mathrm{SP} 2$ \\
0.8 & $0.3 \mathrm{~A}$ & 1.5 & $\mathrm{SP} 3$ \\
0.8 & $0.5 \mathrm{~A}$ & 3.5 & $\mathrm{SP} 4$ \\
\hline
\end{tabular}
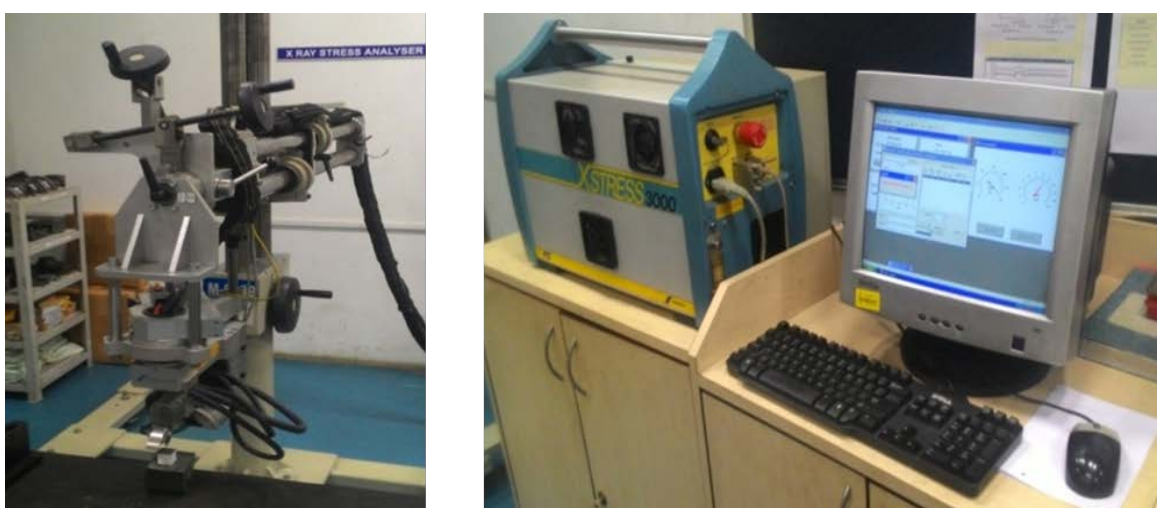

Figure 2. Xstress 3000” measuring device along with electro polishing equipment.

Pin on disk wear testing along with lubrication was carried out on pin-on-disk DUCOM make tribometer. The specimen shown in Figure 3 were manufactured and given planned treatments as already described. Pins with five different types of material conditions (AR, SP1, SP2, SP3 and SP4) were tested. This tribometer works on the Archimedes equation given below [10].

$$
k=\Delta V / F L
$$

where, $k$-wear rate in $\mathrm{mm}^{3} / \mathrm{Nm}, \Delta V$-the worn out volume of material $\left(\mathrm{mm}^{3}\right)$, $F$-normal force and $L$-sliding distance.

Disk and sample pins were cleaned with acetone to avoid any surface contamination. Fresh disk track was used for every new experiment. Water based graphite with 10:2 dilution was used as lubricant during wear testing. This lubricant was supplied continuously over the disk by using small pump motor. Table 3 shows testing parameters which were used during wear testing. The results of wear testing reported in terms of weight loss of pins, wear rate and coefficient of friction. Weight loss of pins were calculated by taking weight of pin before and after testing whereas wear rate was calculated by using Archimedes equation as mentioned above.

\section{Results and Discussion}

\subsection{Microstructural Analysis}

Figure 4 shows SEM images of as received (AR) and shot peened (SP1) surfaces to understand the change in surface characteristics due to shot peening. The surface of as received specimen with polishing finish was smooth, and minor abrasive flaws in polishing direction were observed. On the other hand shot 
Table 3. Sample treatments and their nomenclature.

\begin{tabular}{cc}
\hline Lubricant & Water based graphite \\
\hline Load $(\mathrm{N})$ & 150 \\
Sliding velocity $(\mathrm{m} / \mathrm{s})$ & 0.6 \\
Sliding distance $(\mathrm{m})$ & 1200 \\
\hline
\end{tabular}

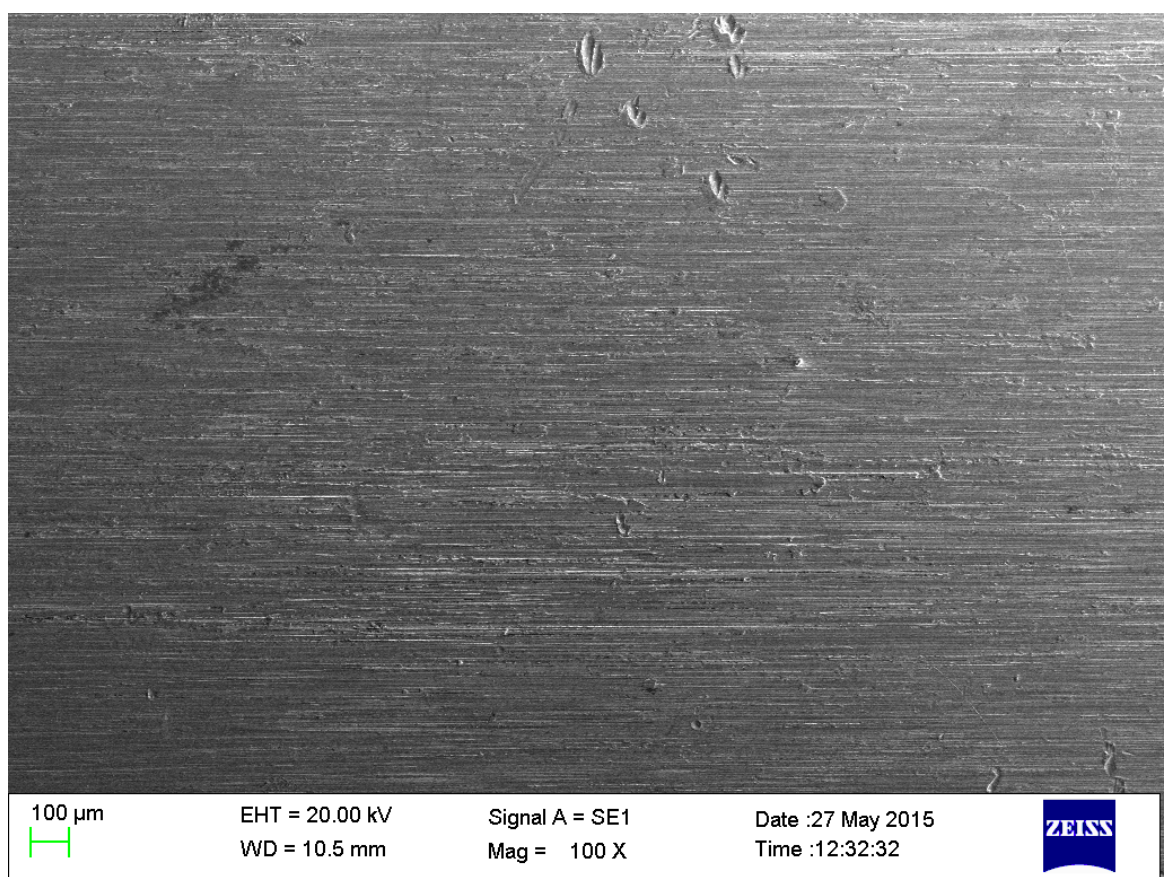

(a)

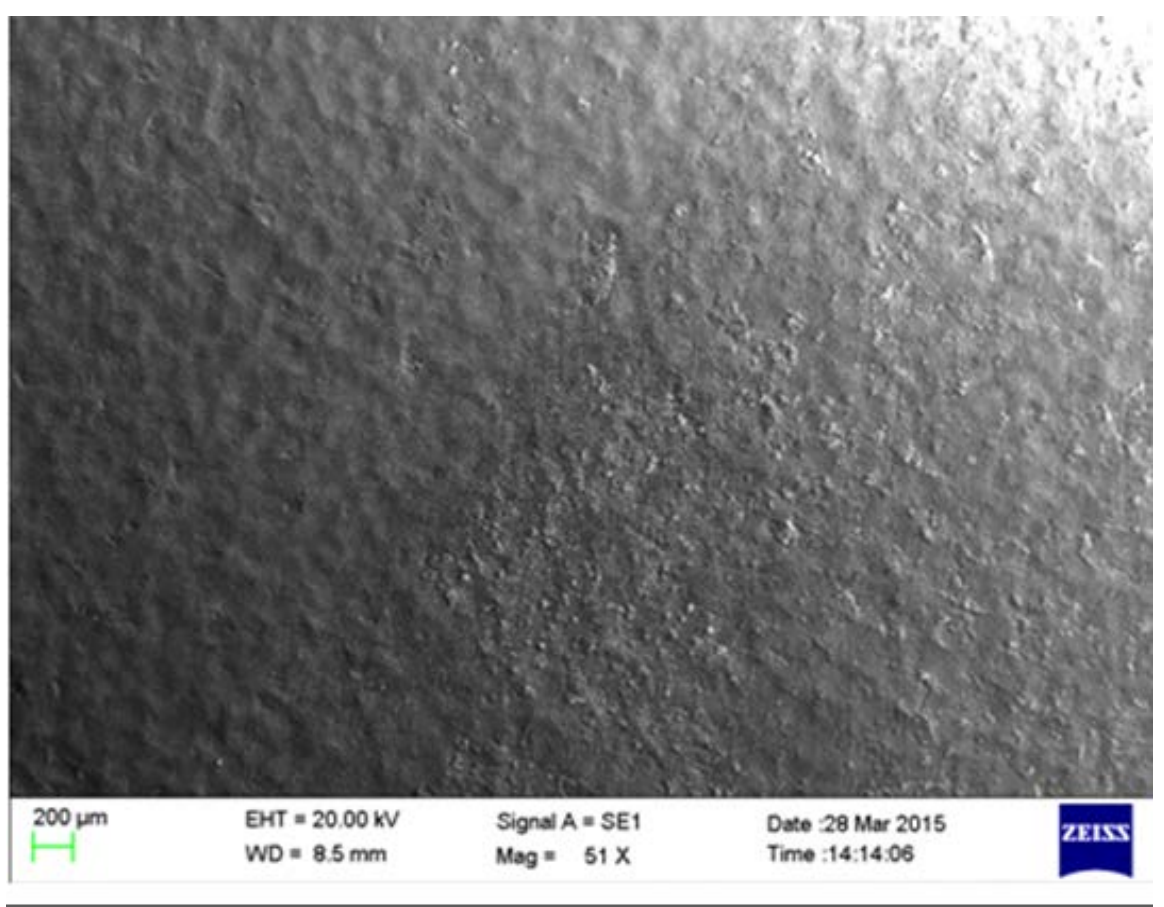

(b)

Figure 4. Surface characteristics of as received and shot peened surface. (a) As Received (AR). (b) Shot Peened (SP1). 
peened surface (Figure 4(b)) had fine dimple like patterns created by bombardment of shots.

The size and shape of dimples depends on shot size and peening intensity used. Above figure shows finest dimple size observed by using $0.4 \mathrm{~mm}$ shot size and 0.3 A Almen peening intensity (SP1). It is observed that, dimple size increases with shot size and peening intensity which further increases surface finish of shot peened specimens. This type of surface modification done by shot peening may result in two conflicting effects associated with tribological behavior. Increase in surface roughness may have adverse effect since it will increase coefficient of friction and intern increase wear rate [11]. Whereas, dimples formed on the surface due to shot peening reduce area of contact and acts as lubricating pockets which may be beneficial for tribological performance of surfaces in contact [12].

\subsection{Surface Roughness}

The surface roughness values obtained for as received and shot peened specimens are presented in Figure 5. All shot peened specimens (SP1, SP2, SP3 and SP4) exhibit higher surface roughness as compared to un treated (as received) specimen. Minimum surface roughness $(1.5 \mu \mathrm{m})$ for shot peened specimens is observed at $0.4 \mathrm{~mm}$ shot size and $0.3 \mathrm{~A}$ peening intensity (SP1).

The relationship between surface roughness and shot peening parameters like shot size and peening intensity also clearly seen from above graph. Increase in surface roughness is observed with increase in shot size and peening intensity. This may be due to increase in surface deformation with increase in shot size and peening intensity. Maximum surface roughness observed at $0.8 \mathrm{~mm}$ shot size and 0.5 A peening intensity (SP4).

\subsection{Micro Hardness}

The hardness distribution along with the surface layers for specimens involving shot peening treatments (SP1, SP2, SP3 and SP4) are shown in Figure 6. Initial material hardness used in this experiment was $30-32$ HRC. Shot peening at optimal condition increases this hardness to $48 \mathrm{HRC}$ at surface which gradually

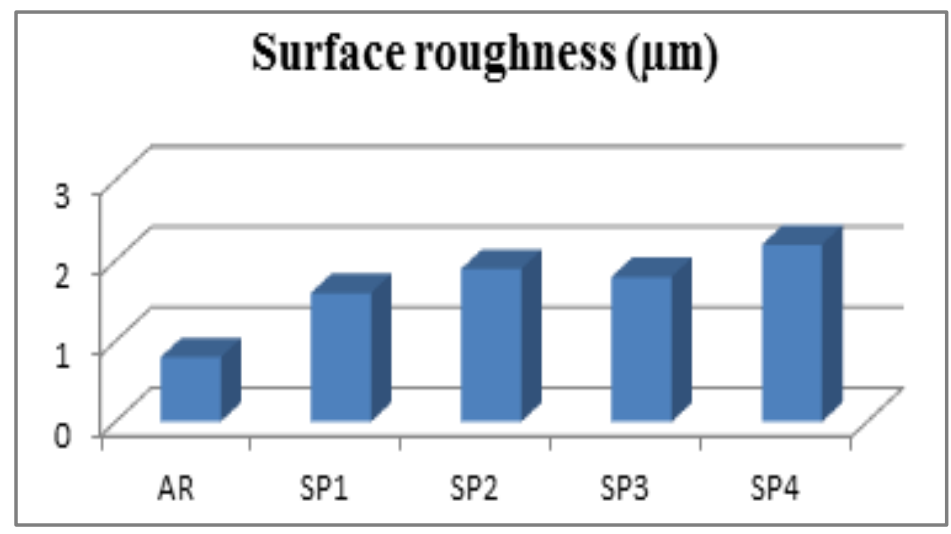

Figure 5. Surface roughness for different specimen treatment conditions. 


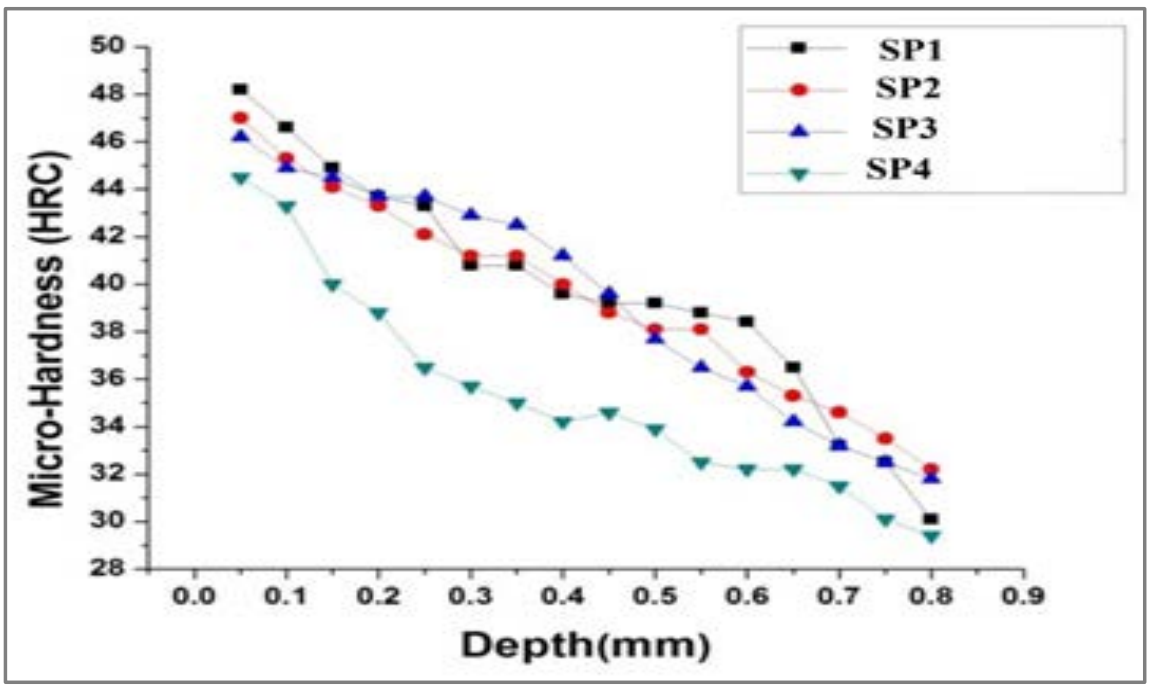

Figure 6. Hardness distribution along with surface layers for shot peened specimens.

decreases along depth. The rise in surface hardness can be attributed due to strain hardening of surface and increase in dislocation density due to shot peening treatment. During the optimal process, shot size used was $0.4 \mathrm{~mm}$ and peening intensity was $0.3 \mathrm{~A}$ (SP1). Maximum surface hardness and case depth was observed for shot peening treatment where lower shot size and peening intensity were used

\subsection{Residual Stresses}

The distribution of the measured residual stress in the thickness direction from the surface for the different shot peening parameters is shown in Figure 7. The values for residual stresses near the surface are similar for all shot peening parameters. The maximum compressive residual stress around $550 \mathrm{MPa}$ and $0.5 \mathrm{~mm}$ case depth are observed for optimal shot peening parameters where shot size of $0.4 \mathrm{~mm}$ and peening intensity of $0.3 \mathrm{~A}$ were used. Significant influence of shot size and peening intensity are also observed. For same size of shots, a compressive stress decreases with increase in peening intensity. It is also observed that compressive stresses decreases with increase in shot size. This indicates that, lower the shot size and peening intensity higher the compressive residual stresses generated during shot peening. This may be due to high amount of plastic deformation induced with larger shot size and peening intensity. With the same shot size, increasing intensity means a higher impact speed. Because of the increased kinetic energy, the degree of plastic deformation and its depth in the sample is significantly increased [13].

\subsection{Wear Performance}

The wear performance of tool steels is very complex phenomenon and it not only depends on the hardness but also on the microstructure, process variables and properties of sliding materials [10]. In the present research work, wear performance in terms of wear rate and coefficient of friction for different specimen 


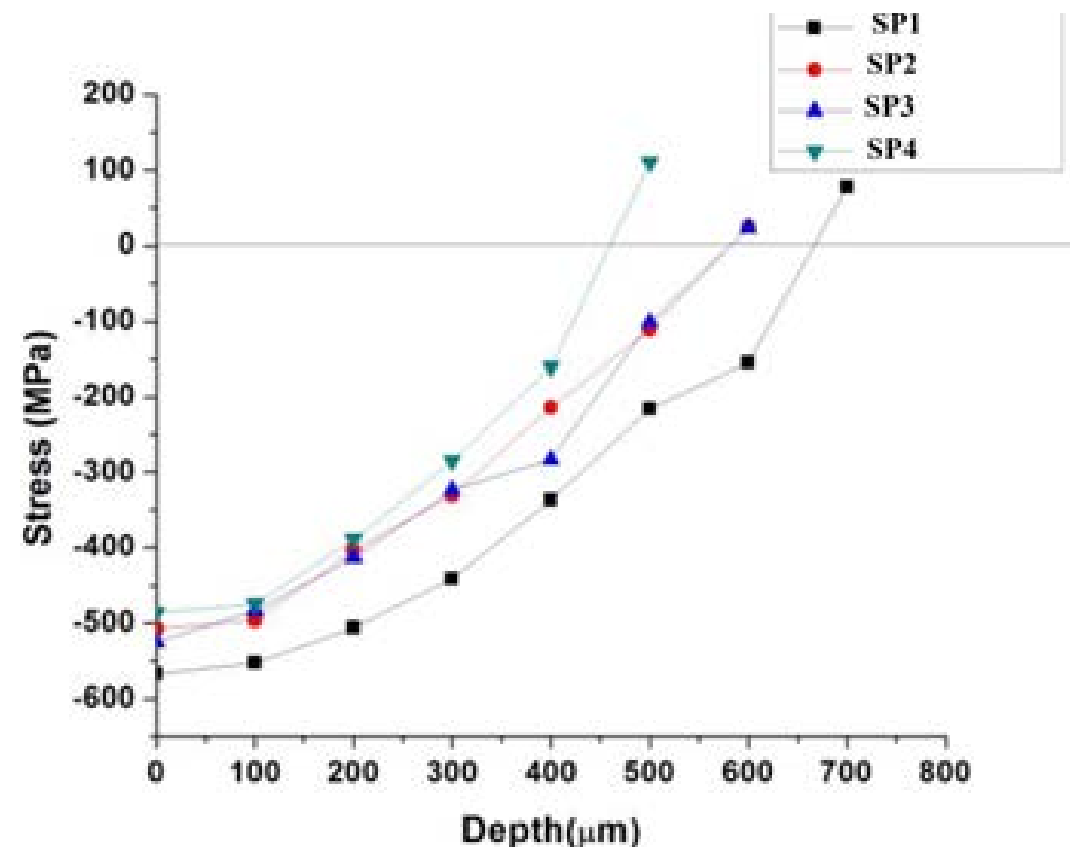

Figure 7. Residual stress distribution along thickness direction for different shot peening parameters.

conditions are measured. The wear rate for different specimen conditions is given in Figure 8(a). The wear rates for all shot peened specimens are significantly lower than conventional as received (AR) specimens. It is clearly due to surface hardness enhancement by strain hardening effect induced during shot peening treatment. Wear rate at optimal shot peening parameter (SP1) is $44 \%$ lower than conventional as received specimen. Figure 8(b) shows coefficient of friction values obtained for various specimen treatment conditions. Both wear rate and coefficient of friction shows similar behavior. There is $19 \%$ reduction in coefficient of friction by using shot peening at optimal parameters (SP1). The correlation between shot peening parameters and coefficient of friction and wear rate can also be clearly seen. Both coefficient of friction and wear rate increases with increase in shot size and peening intensity. This may be due to the fact that, rise in shot size and peening intensity results in higher surface roughness values which adversely affects wear performance.

Shot peening treatment induces three major surface modifications including hardness improvement by strain hardening, compressive residual stress generation and change in surface structure by forming dimple like indentations. Out of these, hardness improvement and compressive stresses generation helps to reduce wear rate whereas surface structure modification may lead to adverse effect since it increases surface roughness. However, dimples formed on the surface due to shot peening reduces area of contact and acts as lubricating pockets which may be beneficial for wear performance of surfaces in contact.

\section{Conclusions}

To summarize, this research discovered the influence of shot peening on DIN 


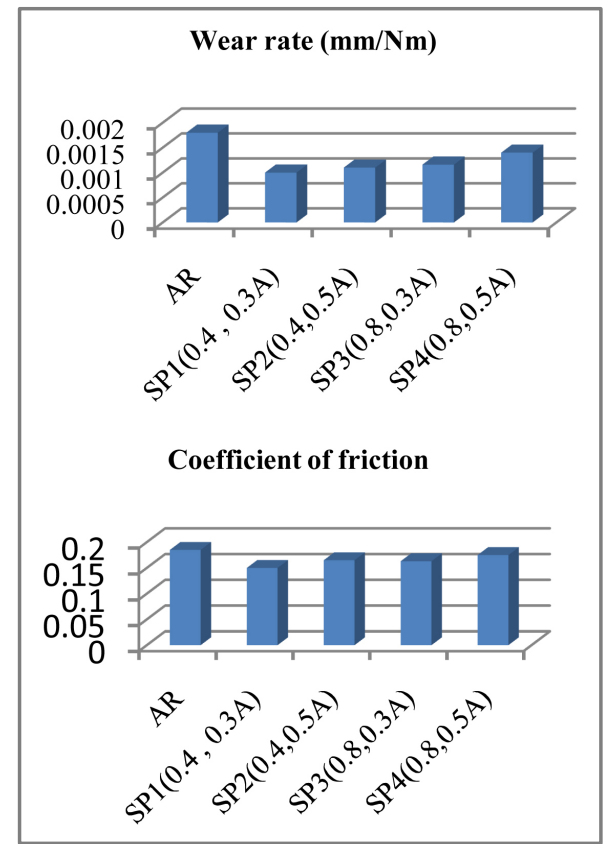

Figure 8. Wear rate and coefficient of friction for different specimen treatment conditions.

1.2714 hot work tool steel analyzed mechanisms behind it. The following conclusions can be drawn from the work:

1) Shot peening causes three major surface characteristic changes residual stresses generation, strain hardening which improves hardness and modifies surface structure by creating dimple like indentations.

2) Shot peening parameters like shot size and peening intensity, significantly influences the behavior of this tool steel. Shot size of $0.4 \mathrm{~mm}$ and 0.3 A peening intensity are the optimal shot peening parameters for DIN 1.2714 tool steel.

3) Lower shot size and peening intensity performs better as compared to their higher values. This is due to increase in plastic deformation, surface damage and surface roughness with increase in shot size and peening intensity.

4) Shot peening at optimal parameters can induce compressive stresses (560 $\mathrm{MPa}$ ) which are more than half times of tensile strength.

5) Shot peening improves surface hardness and can improve wear performance significantly. At optimal parameters, shot peening reduced coefficient of friction and wear rate by $19 \%$ and $44 \%$ respectively.

\section{Acknowledgements}

The authors gratefully acknowledge the extended support provided to this work by KCTI (Kalyani Centre for Technology and Innovation) for providing financial funding, laboratory and library facilities. The authors also acknowledge the support provided by Bharat Forge Ltd., Pune and DSIR (Department of Scientific and Industrial Research), Govt. of India. Finally, the authors would like to express special thanks and gratitude to review committee and top management of Bharat Forge Ltd for granting the permission to publish/present the research 
work. The authors also wish to place their sincere thanks to Diksha engineering pvt. Ltd., Mumbai for providing shot peening experimentation facility.

\section{References}

[1] Kumar, H., Singh, S. and Kumar, P. (2013) Modified shot Peening Process-A Review. International Journal of Engineering Sciences \& Emerging Technologies.

[2] Guagliano, M. and Vergani, L. (2015) Fatigue Crack Growth Behaviour of Nitride and Shot Peened Specimens. Via La Masa, 34-20158 Milano.

[3] Fouad, Y. and El Metwally, M.M. (2011) Effect of Shot Peening on High Cycling Fatigue of Al 2024-T4. International Conference on Advanced Materials Engineering, Singapore, 2011.

[4] Chang, S.-H., Lee, S.-C. and Tang, T.-P. (2008) Effect of Shot Peening Treatment on Forging Die Life. Materials Transactions, 49, 619-623. https://doi.org/10.2320/matertrans.MER2007622

[5] Abood, A.N., Saleh, A.H., Salem1, R.K., Kadhim1, G.A. and Abdullah, Z.W. (2013) Strain Life of Shot Peening AA 2024-T4. Journal of Materials Science Research, 2.

[6] Soady, K.A., Mellor, B.G., Shackleton, J., Morris, A. and Reed, P.A.S. The Effect of Shot Peening on Notched Low Cycle Fatigue. School of Engineering Sciences, University of Southampton, UK.

[7] Vielma, A.T., Llaneza, V. and Belzunce, F.J. (2014) Shot Peening Intensity Optimization to Increase the Fatigue Life of a Quenched and Tempered Structural Steel. XVII International Colloquium on Mechanical Fatigue of Metals (ICMFM17).

[8] Farrahi, G.H. and Ghadbeigi, H. (2006) An Investigation into the Effect of Various Surface Treatments on Fatigue Life of a Tool Steel. Journal of Materials Processing Technology, 174, 318-324. https://doi.org/10.1016/j.jmatprotec.2006.01.014

[9] Harada, Y., Fukauara, K. and Kohamada, S. (2008) Effects of Microshot Peening on Surface Characteristics of High-Speed Tool Steel. Journal of Materials Processing Technology, 201. https://doi.org/10.1016/j.jmatprotec.2007.11.247

[10] Bhavar, V., Khot, S., Kattire, P. and Mehta, M. (2015) Effect of Deep Cryogenic Treatment (DCT) on AISI H13 Tool Steel. Proceedings of the 28th ASM Heat Treating Society Conference, Detroit, 20-22 October 2015.

[11] Zammit, A., Abela, S., Wagner, L., Mhaede, M. and Grech, M. (2013) Tribological Behaviour of Shot Peened Cu-Ni Austempered Ductile Iron. Wear, 302, 829-836. https://doi.org/10.1016/j.wear.2012.12.027

[12] Babić, M., Mitrović, S., Adamović, D., Džunić, D. and Živić, F. The Effect of Shot Peening on Tribological Behavior of Alloyed Steels. Faculty of Mechanical Engineering, Sestre Janjic 6, Kragujevac, Serbia.

[13] Lundberg, M., Peng, R.L., Ahmad, M., Vuoristo, T., Bäckströme, D. and Johansson, S. Influence of Shot Peening Parameters on Residual Stresses in Flake and Vermicular Cast Irons. Department of Management and Engineering, Linköping University, Linköping, Sweden. 
Submit or recommend next manuscript to SCIRP and we will provide best service for you:

Accepting pre-submission inquiries through Email, Facebook, LinkedIn, Twitter, etc. A wide selection of journals (inclusive of 9 subjects, more than 200 journals)

Providing 24-hour high-quality service

User-friendly online submission system

Fair and swift peer-review system

Efficient typesetting and proofreading procedure

Display of the result of downloads and visits, as well as the number of cited articles Maximum dissemination of your research work

Submit your manuscript at: http://papersubmission.scirp.org/

Or contact msce@scirp.org 